\title{
High resolution mapping of nighttime light and air pollutants during the COVID-19 lockdown in Wuhan
}

\author{
Sheng Zheng ${ }^{1,2,3} \cdot$ Y Yuyuan $\mathrm{Fu}^{1} \cdot$ Yu Sun ${ }^{1} \cdot$ Chengjie Zhang $^{1} \cdot$ Yueshe Wang $^{4} \cdot$ Eric Lichtfouse $^{4,5}(\mathbb{D}$
}

Received: 16 December 2020 / Accepted: 10 March 2021 / Published online: 23 March 2021

(c) The Author(s), under exclusive licence to Springer Nature Switzerland AG 2021

\begin{abstract}
The novel coronavirus (COVID-19) has induced unprecedented improvements of air quality due to drastic shrinking of human activities during the pandemic lockdown in 2020. While declines of most air pollutants have been globally evidenced in most cities worldwide, there is few detailed spatial knowledge at local scale. Therefore, we present here a high resolution mapping of the 2018-2020 evolution of human activities and air pollutants in Wuhan. Human activities were assessed by nighttime light radiance. We measured the air quality index (AQI) as the maximum value among air quality sub-indices of $\mathrm{SO}_{2}, \mathrm{NO}_{2}, \mathrm{CO}, \mathrm{O}_{3}$ and particulate matter. We also compared mean monthly pollutant concentration during January-April in 2018, 2019 and 2020. Mapping results show that variations of nighttime light radiance were heterogenous at local scale, showing both rises and declines in the same district. The radiance decreased in eight districts located mostly in the city center, as a result of lower human activity, but the radiance increased in the five surrounding districts, as a consequence of people staying at home. AQI was low during lockdown, averaging at 57, but showed strong daily variations with a slight pollution around February 5 with AQI rising to 126 . During this pollution event, particulate matter, $\mathrm{SO}_{2}, \mathrm{NO}_{2}$ and $\mathrm{CO}$ levels were positively correlated, suggesting common sources, but were not correlated with ozone; and particulate matter, $\mathrm{SO}_{2}, \mathrm{NO}_{2}$ and $\mathrm{CO}$ decreased with relative humidity, suggesting removal by precipitation. Comparison of 2020 data with previous years shows that particulate matter and $\mathrm{NO}_{2}$ were highly reduced, $\mathrm{CO}$ was less reduced due to ongoing power industries, $\mathrm{SO}_{2}$ first declined then increased to exceed 2018-19 values due to coal combustion, and ozone levels was more abundant due both to less $\mathrm{NO}_{\mathrm{x}}$ pollution and the weekend effect.
\end{abstract}

Keywords COVID-19 $\cdot$ Air quality $\cdot$ Human activity $\cdot$ Wuhan

\section{Introduction}

The outbreak and spread of the novel coronavirus (COVID-19) has become a major public health event threatening the safety of the population and social stability

\footnotetext{
Sheng Zheng

shengzheng@zju.edu.cn

Eric Lichtfouse

eric.lichtfouse@gmail.com

1 Department of Land Management, Zhejiang University, Hangzhou 310058, People's Republic of China

2 Collaborative Innovation Center of Atmospheric Environment and Equipment Technology, Jiangsu Key Laboratory of Atmospheric Environment Monitoring and Pollution Control (AEMPC), Nanjing University of Information Science \& Technology, Nanjing 210044, People's Republic of China
}

(Liu et al. 2020a; Wang et al. 2020a). On December 9, 2020, a total of 67,780,361 confirmed cases of COVID19 have been reported worldwide, and 94,500 confirmed cases in China (https://covid19.who.int/table), and Wuhan City in Hubei Province reported 68,149 confirmed cases

3 Shanghai Key Laboratory of Atmospheric Particle Pollution and Prevention (LAP3), Department of Environmental Science and Engineering, Fudan University, Shanghai 200433, People's Republic of China

4 State Key Laboratory of Multiphase Flow in Power Engineering, Xi' an Jiaotong University, Xi' an 710049, People's Republic of China

5 Aix-Marseille Univ, CNRS, IRD, INRA, Coll France, CEREGE, Aix en Provence 13100, France 
in total (https://voice.baidu.com/act/newpneumonia/newpn eumonia). In order to prevent the virus from spreading rapidly with the movement of the population, Wuhan City was completely shut down from January 23 until April 7, thus lasting 76 days.

A decline of atmospheric pollution has been observed in many cities and nations worldwide as a consequence of lower vehicle traffic, industrial activities and pollutant emissions (Bao and Zhang 2020; He et al. 2020; Lian et al. 2020; Zheng et al. 2020). For instance, the Royal Belgian Institute for Space Aeronomy studied the effect of the COVID-19 on air quality and found that tropospheric $\mathrm{NO}_{2}$ above major cities in China decreased by $30-50 \%$ early 2020 compared to 2019 (https://www.aeronomie.be/ en/news/2020/tropomi-observes-impact-corona-virus-airquality-china). Air pollution has highly decreased during city lockdown, and air quality improvements were larger in colder, richer and more industrialized cities (He et al. 2020). A study of 44 cities in northern China showed an average $7.80 \%$ decline of the air quality index (AQI, Bao and Zhang 2020). Specifically, concentrations of airborne particulate matter $\left(\mathrm{PM}_{2.5}\right)$ decreased by $35 \%$ and concentrations of nitrogen dioxide $\left(\mathrm{NO}_{2}\right)$ declined by $60 \%$ in January 23-February 29 versus January 1-22, 2020 (Shi and Brasseur 2020). Lower $\mathrm{SO}_{2}, \mathrm{NO}_{\mathrm{x}}$ and $\mathrm{PM}_{2.5}$ emissions over the Yangtze River Delta region were explained by reduced industrial operations, constructions and vehicle traffic (Li et al. 2020). Similar improvement of air quality was observed in central China, including Wuhan (Xu et al. 2020).

Wuhan is one of the most densely populated Chinese cities with a permanent resident population of 11.212 million in 2019. The major sources of air pollution in Wuhan are emissions from coal-fired enterprises, vehicle emissions and pollution from biomass burning from the surrounding countryside (Liu et al. 2020b). During lockdown, local public transportation was suspended, and the movement of people into and out of the city was interrupted. The vehicle numbers in Wuhan dropped at least $63.31 \%$, and the dropping percentages of ring road and high-level road traffic were $84.81 \%$ and $80.22 \%$, respectively (Wu et al. 2020). In mid-February, Wuhan lockdown measures were further strengthened with management of all residential communities (Pan et al. 2020). While global reduction of air pollutants has been evidenced in most cities worldwide, there is few detailed knowledge on the spatial evolution of pollution at the local scale. Therefore, we present here a high resolution mapping of human activities using nighttime light radiance, and the temporal variations of air pollutants $\mathrm{PM}_{2.5}, \mathrm{PM}_{10}, \mathrm{SO}_{2}, \mathrm{CO}, \mathrm{NO}_{2}$ and $\mathrm{O}_{3}$ during the COVID-19 lockdown in Wuhan.

\section{Experimental}

\section{Study area}

As the capital of Hubei Province, Wuhan is a central city in central China and in the Yangtze River Economic Zone. Belonging to subtropical monsoon humid climate, Wuhan has abundant sunshine and rainfall with an annual average temperature of $15.8-17.5{ }^{\circ} \mathrm{C}$; the rainfall being predominant in June-August. Wuhan has developed roads, railway, water and air transportation, and it is a key industrial city in China. The whole Wuhan covers an area of $8,569.15 \mathrm{~km}^{2}$. Up to the end of 2019 , the whole city had realized gross domestic product of CNY 1,622.321 billion with permanent resident population of 11,212,000, and the urbanization rate in 2019 was $80.49 \%$.

Wuhan has 13 administrative districts, including seven central districts including Jiangan, Jianghan, Qiaokou, Hanyang, Wuchang, Qingshan and Hongshan, and six new urban districts: Caidian, Jiangxia, Huangpi, Xinzhou, Dongxihu and Hannan. Jianghan and Jiangan districts are core commercial development areas in Wuhan, and all kinds of business centers are mostly concentrated in these areas. The commercial development is quite balanced in Hongshan and Wuchang districts. Liu et al. (2020c) chose 91 sub-districts, i.e., at the block or the street scale, within central districts, and found that $63 \%$ of subdistricts of Jiangan, Jianghan and Qiaokou are commercial, and 78\% of educational sub-districts are in Wuchang, Qingshan and Hongshan. However, the development of business centers in peripheral city areas and suburban areas in Wuhan relatively lags behind with partially low agglomeration degree and smaller scale as well as single function types. Except for Jiangxia and Dongxihu districts, no business centers conforming to planning expectations are formed (Kang et al. 2018; Xu et al. 2019). Besides, Wuhan embraces over 80 colleges and universities, which are also mainly concentrated in Wuchang, Hongshan and Qingshan districts. There are 10 state-controlled air pollution monitoring sites located in Wuhan City (Fig. 1, Table S1).

\section{Data sources}

Air quality data in the first four months of 2018, 2019 and 2020 in the 10 state-controlled monitoring sites of Wuhan were acquired from the China Environmental Monitoring Centre (CNEMC) at http://www.cnemc.cn. In addition, the "mean" defined in this study was the arithmetic mean value of hourly values. The mass concentration of one air pollutant in Wuhan was the mean value of the concentrations of this pollutant measured at nine state-controlled 
Fig. 1 Spatial distribution of the 10 state-controlled air pollution monitoring sites located in Wuhan City

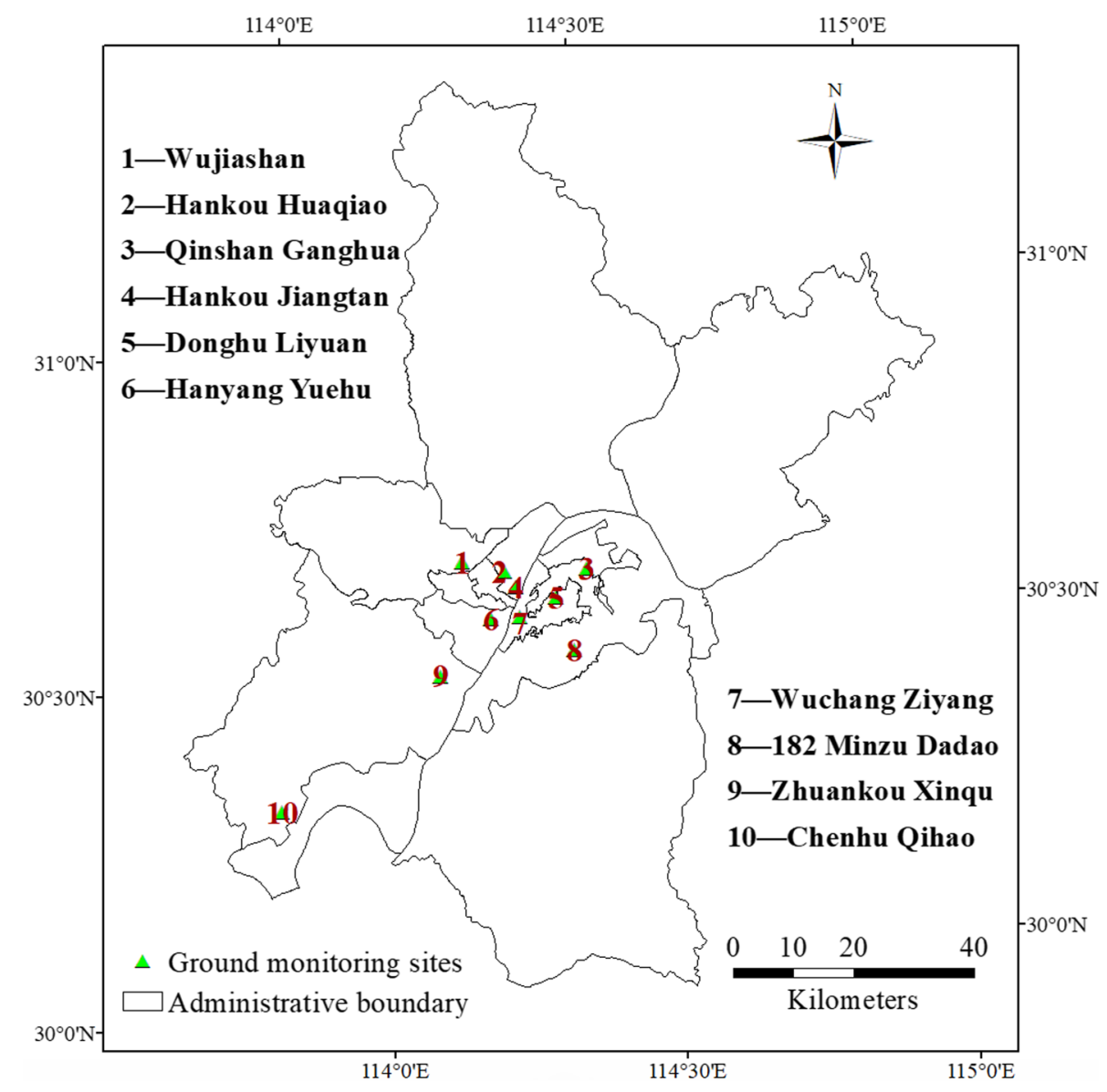

monitoring stations. Chenhu Qihao, as the urban background site, was not included into the mean value of the whole city.

Hourly meteorological parameters including temperature in ${ }^{\circ} \mathrm{C}$, relative humidity in $\%$, and 10 -min average wind speed in $\mathrm{m} / \mathrm{s}$ were acquired from Hubei Meteorological Service at http://hb.cma.gov.cn. The nighttime light (NTL) data were taken from Visible Infrared Imaging Radiometer Suite (VIIRS) onboard the Suomi National Polar-orbiting Partnership (Suomi-NPP, Zhang et al. 2017). The NPP-VIIRS Day/ Night Band (DNB) month composite data in December 2019 and February 2020 were collected. The monthly average of NPP-VIRRS data were obtained from the website of Earth Observations Group (https://eogdata.mines.edu/download_ dnb_composites.html).

\section{Nighttime light}

Nighttime light (NTL) data have been extensively used to investigate scenarios related to human social activities, such as dynamic monitoring of urban expansion (Ma et al. 2015), and estimation of energy consumption (Sun et al. 2020). In order to mitigate the pandemic, people were required to reduce unnecessary outings and gatherings. NTL data can thus be used as an auxiliary means to study the changes of production and life during the COVID-19 in Wuhan. The spatial resolution of the monthly NTL data from the Earth Observations Group is 15 arc-seconds. Each pixel of the NTL data contains information on the mean detected radiance, with unit of $\mathrm{nW} / \mathrm{cm}^{2} / \mathrm{sr}$.

\section{Air quality index}

According to the Technical Regulation on Ambient Air Quality Index (on trial), AQI is the maximum among air quality sub-indices of the following pollutants: $\mathrm{SO}_{2}, \mathrm{NO}_{2}$, $\mathrm{CO}, \mathrm{O}_{3}, \mathrm{PM}_{10}$ and $\mathrm{PM}_{2.5}$ (Zheng et al. 2014), shown in Eq. $(1,2)$.

$\mathrm{IAQI}_{\mathrm{P}}=\frac{\mathrm{IAQI}_{\mathrm{Hi}}-\mathrm{IAQI}_{\mathrm{Lo}}}{\mathrm{BP}_{\mathrm{Hi}}-\mathrm{BP}_{\mathrm{Lo}}}\left(C_{\mathrm{P}}-\mathrm{BP}_{\mathrm{Lo}}\right)+\mathrm{IAQI}_{\mathrm{Lo}}$

$\mathrm{AQI}=\max \left(\mathrm{IAQI}_{1}, \mathrm{IAQI}_{2}, \mathrm{IAQI}_{3}, \ldots, \mathrm{IAQI}_{\mathrm{n}}\right)$

where IAQI $I_{P}$ refers to the air quality sub-index of pollutant $\mathrm{P} ; C_{\mathrm{P}}$ represents the mass concentration of pollutant $\mathrm{P} ; \mathrm{BP}_{\mathrm{Hi}}$ is the breakpoint that is greater than or equal to $C_{\mathrm{P}} ; \mathrm{BP}_{\mathrm{Lo}}$ is the breakpoint that is less than or equal to $C_{\mathrm{P}} ; \mathrm{IAQI}_{\mathrm{Hi}}$ is the 
air quality sub-index corresponding to $\mathrm{BP}_{\mathrm{Hi}}$; $\mathrm{IAQI}_{\mathrm{Lo}}$ is the air quality sub-index corresponding to $\mathrm{BP}_{\mathrm{Lo}} ; n$ is the number of air pollutants. IAQI and corresponding thresholds of each pollutants is shown in Table S2. The AQI value is divided into six grades:

1. 0-50: superior air quality;

2. 51-100: good air quality;

3. 101-150: mild air pollution;

4. 151-200: moderate air pollution;

5. 201-300: heavy air pollution;

6. More than 300: severe air pollution.

The air pollutant having the maximum IAQI value when AQI is larger than 50 is defined as the primary pollutant. In this study, the primary pollutant was identified in order to determine which pollutant provided the largest contribution to air quality degradation. The daily AQI in Wuhan was calculated as the average of the AQI at nine state-controlled monitoring stations.

\section{Results and discussion}

\section{Nighttime light radiance to map human activity}

We studied the effect of lockdown on human activities by mapping variations of nighttime light radiance before and during lockdown in Wuhan, green indicating light decline and red denoting light increase (Fig. 2a, b). The sum of radiance variations for each district is given in Fig. $2 c$ and Table S3. Results show first a decrease of radiance for eight districts located mostly in the center, which was expected from the decrease of human activities during lockdown. Yet data also show an increase of radiance in five surrounding districts, which was less expected. Noteworthy, our findings reveal that radiance variation are not uniform and that a high-resolution mapping discloses heterogeneities such as radiance rises and declines at small scale in the same district. We interpret these finding as follows.

The shift of human activities revealed by variation of nighttime light globally agree with changes in human activities. For instance, during the epidemic, the Wuhan government adopted the most rigorous blocking and quarantine policies, and strictly restricted personnel flow and economic activities. The passages from and to Wuhan were cut off, people were required to stop working and stay at home, all unnecessary gatherings and commercial activities were forbidden, only supermarkets in nearly all malls were allowed to open and daily opening hours were greatly shortened (Liu et al. 2020a). As a consequence, the malls and stores in the main commercial districts in the city center were closed, and personnel flow and traffic flow were reduced to a great extent. In addition, most college students did not return to schools due both to holidays and the epidemic in February, and also most schools were blocked.

This explains well our results showing a higher radiance decrease in center districts versus surrounding districts (Fig. 2). Indeed, the central districts are highly urbanized areas with business and bristling colleges and universities. For example, the higher radiance decrease of $-2570 \mathrm{nW} /$ $\mathrm{cm}^{2} / \mathrm{sr}$ was observed in the Hongshan district, which contains prosperous business centers in the Optics Valley and 38 higher learning institutions. On the contrary, the surrounding, more rural districts showed an increase of radiance, up to $1516 \mathrm{nW} / \mathrm{cm}^{2} / \mathrm{sr}$ for the Jiangxia district. This could be explained by the presence of residential areas where citizens stayed at home during the epidemic instead of moving daily to the city center, in agreement with a previous report (Liu et al. 2020a).

Overall, variations of nighttime light radiance show both expected declines in the city center and less expected rises in surrounding districts. High resolution mapping also reveals heterogeneous variations at low scale in the same district, e.g., radiance increase in some areas and radiance decrease in other areas. Radiance decrease is explained by decreasing activities in the center, whereas radiance increase denotes staying-home people in surrounding districts.

\section{Global air quality during the lockdown}

We assessed air quality in Wuhan during lockdown using the air quality index (AQI), which is the highest value among air quality sub-indices of the following pollutants: $\mathrm{SO}_{2}, \mathrm{NO}_{2}, \mathrm{CO}, \mathrm{O}_{3}, \mathrm{PM}_{10}$ and $\mathrm{PM}_{2.5}$ (Fig. 3, Table S4). Results showed that almost all data are within the two best air quality categories: I for superior air quality and II for good air quality. These findings are explained by the strict blocking policy in Wuhan which induced an extreme reduction of pollutant emissions, as expected. Yet, surprisingly, a mild pollution event still took place after lockdown, as previously observed by Lian et al. (2020). Specifically, air pollution increased from January 26 with mean AQI of 43 to February 5 with mean AQI of 126. On February 5, AQI rised from 79 at $00 \mathrm{~h} 00$ to 183 at $11 \mathrm{~h} 00$, then declined to 79 at $18 \mathrm{~h} 00$, then rised again to 169 at $21 \mathrm{~h} 00$, then declined. In addition, the primary pollutant on February 5 was $\mathrm{PM}_{2.5}$, meaning that $\mathrm{PM}_{2.5}$ provided the largest contribution to air quality degradation. Overall, we observed a slight pollution event peaking on February 5 during lockdown, which is likely due to agricultural production, domestic heating and solid waste combustion. 

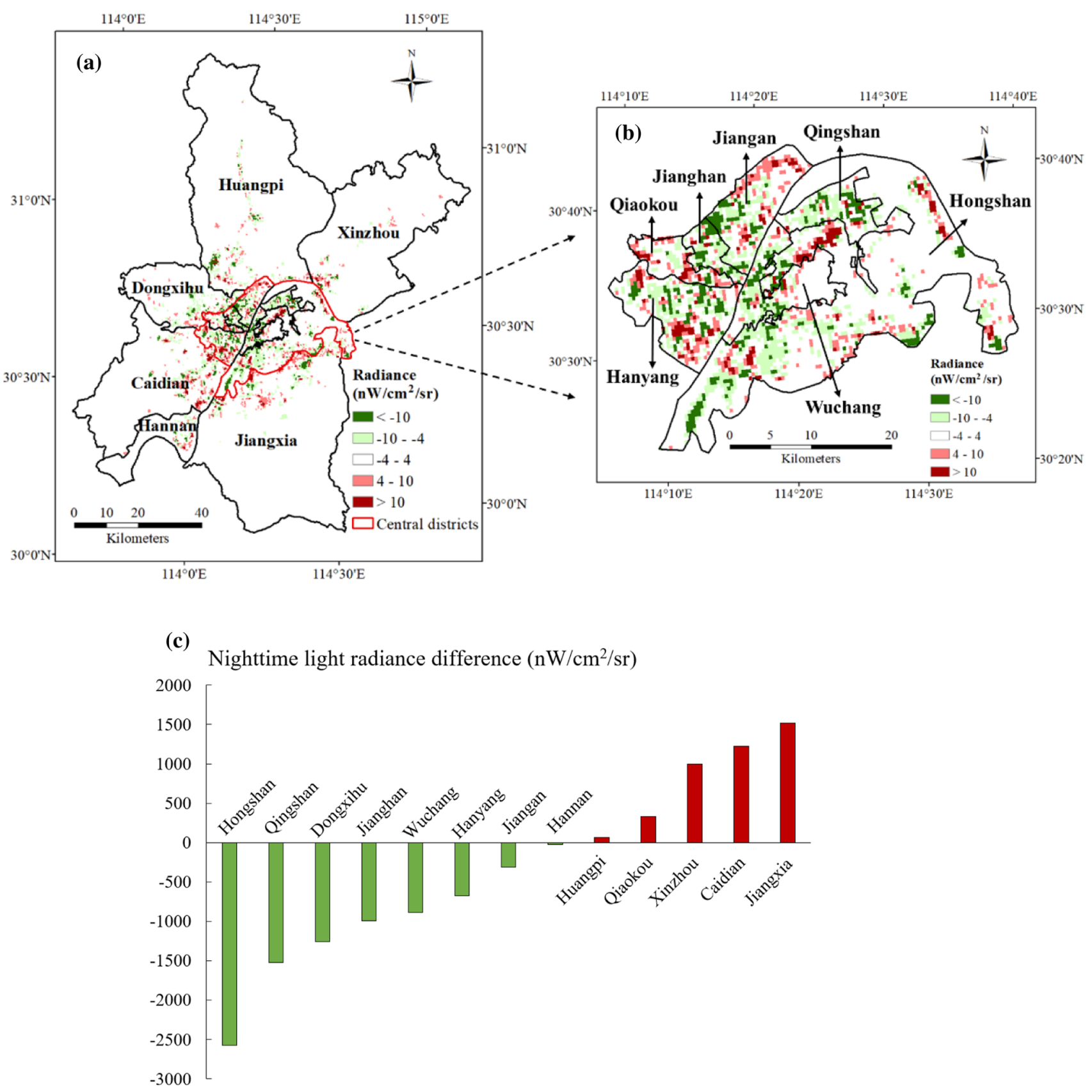

Fig. 2 a, b Variations of nighttime light (NTL) radiance in Wuhan from December 2019 to February 2020, as monthly averages. Green indicates less radiance whereas red denotes more radiance. c Sum of NTL radiance variations in each district in Wuhan

\section{Correlation of air pollutants and meteorological factors}

We correlated levels of hourly air pollutants during February 4-6 (Table S5 and S6). Results show that particulate matter levels, e.g., $\mathrm{PM}_{2.5}$ and $\mathrm{PM}_{10}$, increased with $\mathrm{SO}_{2}, \mathrm{NO}_{2}$ and $\mathrm{CO}$ concentrations with correlation coefficients ranging from 0.44 for $\mathrm{NO}_{2}$ to 0.92 for $\mathrm{CO}$, with $p$ lower than 0.01 . This finding could be explained by emissions from sources generating both particulate matter and gases, such as fuel combustion, industrial and agricultural production. CO sources include motor vehicle exhausts, power plants, heating boiler, domestic stove and solid waste combustion. Since vehicle traffic and industrial activities have decreased during lockdown, the most likely sources are power plants, agricultural production, domestic heating and solid waste combustion. On the other hand, ozone levels were not correlated with particulate matter concentration, and ozone levels increased with decreasing $\mathrm{NO}_{2}$ levels, with a -0.44 coefficient. Similar trends have been observed in Hangzhou 
Fig. 3 Daily air quality index (AQI) in Wuhan during the lockdown period from January 23 to April 7, 2020. Arrow shows a mild pollution episode on February 5. AQI is the maximum among air quality sub-indices of the following pollutants: $\mathrm{SO}_{2}, \mathrm{NO}_{2}, \mathrm{CO}, \mathrm{O}_{3}$, $\mathrm{PM}_{10}$ and $\mathrm{PM}_{2.5}$. The daily AQI in Wuhan was obtained by averaging the AQI at 9 monitoring sites

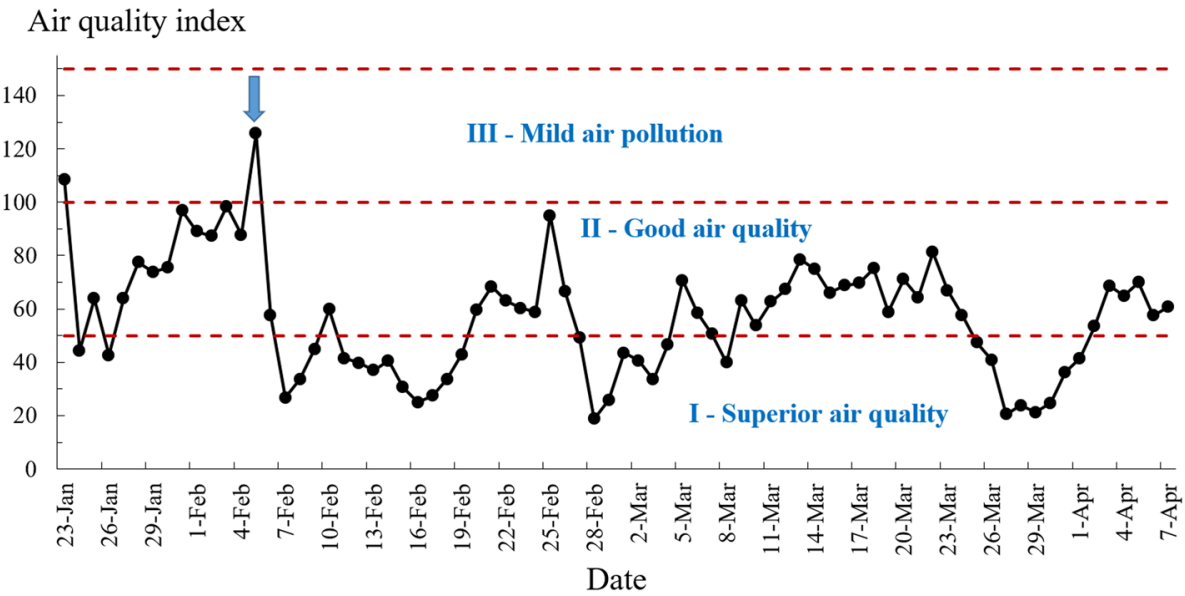

during lockdown and are explained by chemical titration of ozone by nitrogen oxides, e.g., NO (Wang et al. 2020b).

We also correlated levels of hourly air pollutants and meteorological factors during February 4-6 (Table S6). Temperature was positively correlated with the concentrations of all pollutants except for $\mathrm{O}_{3}$, with a maximum coefficient of 0.68 for $\mathrm{PM}_{2.5}$, followed 0.57 for $\mathrm{PM}_{10}$ and 0.54 for $\mathrm{CO}$. This is probably due to the fact that temperature favors most chemical reactions in the atmosphere. Relative humidity was negatively correlated with the concentrations of all pollutants except for $\mathrm{O}_{3}$, with a maximum correlation of -0.40 with $\mathrm{PM}_{2.5}$. This is likely due to the removal of particles and gaseous pollutants by adsorption on water droplets followed by fall down and deposition at high humidity. For instance relative humidity was higher than $90 \%$ on February 6, thus explaining the low AQI at this date, of 57 (Fig. 3). Last, the slight positive correlations observed between wind speed and particulate matter (Table S6) suggests that wind transport contribute to the accumulation of particulate matter in some places.

Overall, particulate matter increases with $\mathrm{SO}_{2}, \mathrm{NO}_{2}$ and $\mathrm{CO}$ levels, suggesting a common source, but is not correlated with ozone, suggesting a different source. Ozone increases with decreasing $\mathrm{NO}_{2}$ levels, which is explained by chemical titration. Except for ozone, pollutant levels decrease with relative humidity, which suggests removal of pollutants by precipitation.

\section{Temporal evolution of air pollutants}

We compared the evolution of mean monthly concentration of $\mathrm{PM}_{2.5}, \mathrm{PM}_{10}, \mathrm{SO}_{2}, \mathrm{CO}, \mathrm{NO}_{2}$ and $\mathrm{O}_{3}$ in Wuhan during January-April in 2018, 2019 and 2020 (Fig. 4, Table S7). In 2020, mean concentrations of $\mathrm{PM}_{2.5}, \mathrm{PM}_{10}, \mathrm{NO}_{2}$ decreased by $31.9 \%, 31.5 \%, 37.9 \%$, respectively, versus 2019 , and by $34.3 \%, 46 \%, 45.6 \%$, respectively, versus 2018 , similarly to a previous study (Xu et al. 2020). These findings are explained by blocking and shutdown policies adopted by the Wuhan government during the epidemic. The decrease of $\mathrm{PM}_{10}$ and $\mathrm{PM}_{2.5}$ concentrations is explained by less motor vehicle exhausts, industrial activity and biomass burning (Fig. 4a,b). Indeed, the sources of $\mathrm{PM}_{2.5}$ in Wuhan are $27.1 \%$ from motor vehicles, $26.8 \%$ from secondary sulfate and nitrate, $26.4 \%$ from the industry and $19.6 \%$ from biomass burning according to Cheng et al. (2012).

While $\mathrm{SO}_{2}$ levels were much lower in January 2020 versus 2018 and 2019, $\mathrm{SO}_{2}$ levels increased with time in 2020 to exceed 2018-19 levels in April (Fig. 4c). This finding is explained by the fact that the fire coal industry never stopped operation during lockdown, because coal combustion generates gaseous $\mathrm{SO}_{2}$. The rising $\mathrm{SO}_{2}$ in 2020 may also result from the increase in coal consumption for domestic heating (Wang et al. 2020b).

The decline of mean CO levels in 2020 was rather lower than most pollutants, of $17.0 \%$ versus 2018 and $18.7 \%$ versus 2019 (Fig. 4d). This is explained by the fact that shutdown policies have been specifically applied to labor-intensive light industry, whereas thermal power generation, steel and coking industries were not stopped. Mean $\mathrm{NO}_{2}$ levels decreased sharply in 2020 with a $45.6 \%$ drop versus 2018 , and a $37.9 \%$ drop versus 2019 (Fig. 4e). This is due to the cessation of vehicle traffic and, in turn, to the sharp reduction of traffic emissions (Huang et al. 2020; Xu et al. 2020).

Mean ozone levels in 2020 increased by $32.1 \%$ versus 2018 and by $43.6 \%$ versus 2019 (Fig. 4f). Ozone levels also increased from January to April. Ozone rise during lockdown have been previously also observed in Wuhan and other cities (Huang et al. 2020; Wang et al. 2020b; Xu et al. 2020). Both ozone rises in 2020 versus 2018-19 and from January to April are explained by lower $\mathrm{NO}_{\mathrm{x}}$ pollution. Indeed, near-ground ozone is mainly produced under light conditions by precursors such as $\mathrm{CO}, \mathrm{NO}_{\mathrm{x}}$ and volatile organic compounds (VOCs) (Huang et al. 2020). This explains the ozone increase from January to April due to 
(a)

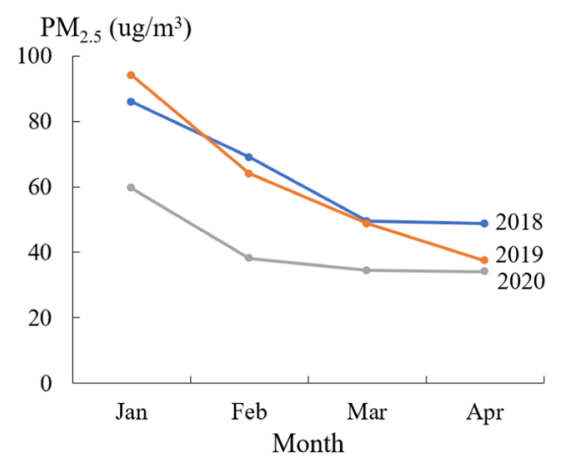

(d)

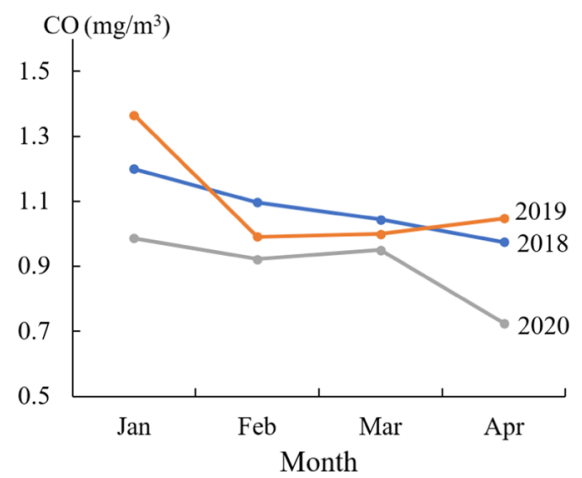

(b)

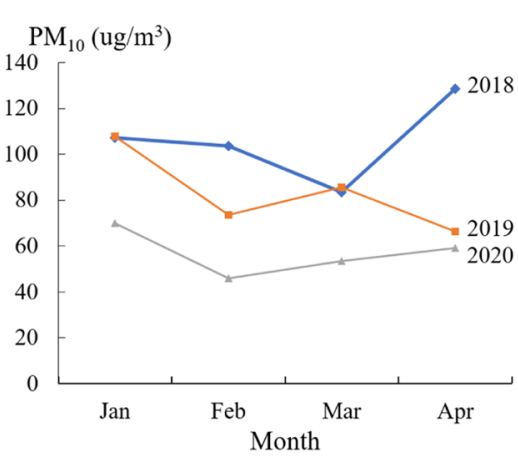

(e)

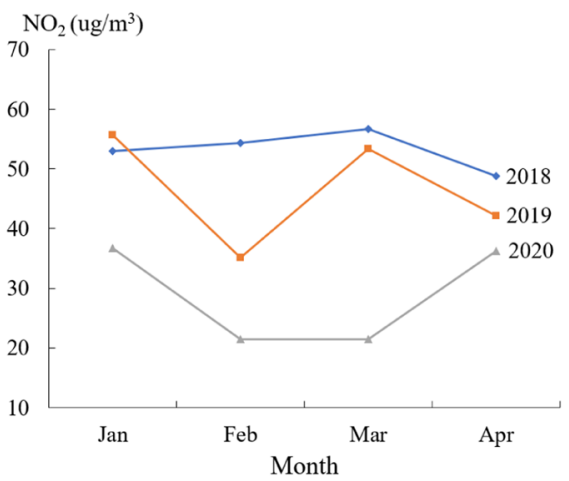

(c)

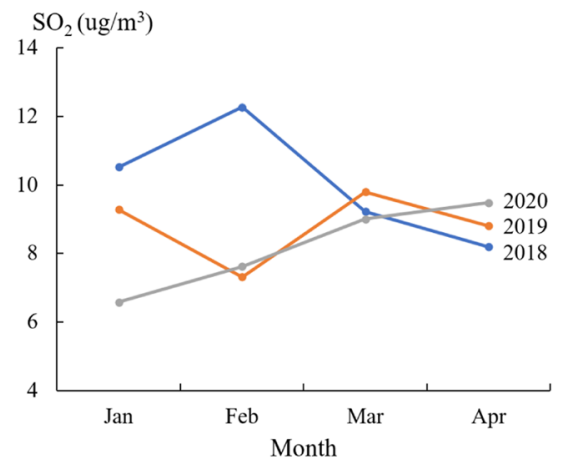

(f)

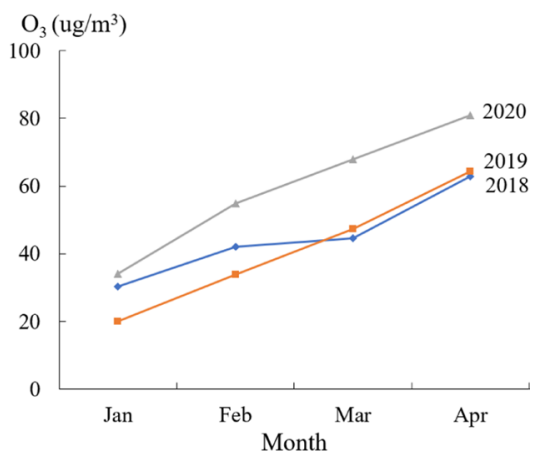

Fig. 4 Monthly concentration of $\mathrm{PM}_{2.5}$ (a), $\mathrm{PM}_{10}$ (b), $\mathrm{SO}_{2}$ (c), $\mathrm{CO}$ (d), $\mathrm{NO}_{2}$ (e) and $\mathrm{O}_{3}(\mathbf{f})$. The monthly mean concentrations of $\mathrm{PM}_{2.5}$, $\mathrm{PM}_{10}$ and $\mathrm{NO}_{2}$ were decreased obviously, in comparison with those in the same period of 2019 and 2018. The monthly CO concentration

rising daylight time period (https://www.timeanddate.com/ sun/china/wuhan). The increase of ozone during lockdown is explained by the decrease in $\mathrm{NO}_{\mathrm{x}}$. Indeed, the production of ozone from $\mathrm{CO}$ is initiated by free radicals such as the hydroxyl radical as follows; a similar reaction occurs by replacing CO by VOCs (https://en.wikipedia.org/wiki/Tropo spheric_ozone):

$\cdot \mathrm{OH}+\mathrm{CO} \rightarrow \cdot \mathrm{HOCO}$

$\cdot \mathrm{HOCO}+\mathrm{O}_{2} \rightarrow \mathrm{HO}_{2} \cdot+\mathrm{CO}_{2}$

$\mathrm{HO}_{2} \cdot+\mathrm{NO} \rightarrow \cdot \mathrm{OH}+\mathrm{NO}_{2}$

$\mathrm{NO}_{2}+\mathrm{h} v \rightarrow \mathrm{NO}+\mathrm{O}\left({ }^{3} \mathrm{P}\right)$

$\mathrm{O}\left({ }^{3} \mathrm{P}\right)+\mathrm{O}_{2} \rightarrow \mathrm{O}_{3}$

During periods of high pollution, ozone production is moderated by the excess of $\mathrm{NO}_{\mathrm{x}}$, because $\mathrm{NO}_{\mathrm{x}}$ reacts with also reduced in comparison with those in the same period of 2019 and 2018, while the decrease amplitude was small. High concentration of $\mathrm{O}_{3}$ was found during the lockdown

radicals and thus decrease ozone yield. Whereas during lockdown, less radicals are scavenged by $\mathrm{NO}_{\mathrm{x}}$ because $\mathrm{NO}_{\mathrm{x}}$ levels are lower, and, in turn ozone production is higher under sunlight. High ozone levels are also associated with low levels of particulate matter and strong solar radiation as a result of the "weekend effect" (Murphy et al. 2007). Reports of ozone pollution in other cities during the lockdown have reached similar conclusions ( $\mathrm{Li}$ and Tartarini 2020; Wang et al. 2020b).

Overall, $\mathrm{PM}_{2.5}, \mathrm{PM}_{10}$ and $\mathrm{NO}_{2}$ were highly reduced in the 2020 lockdown versus 2018 and 2019, which is explained by the halt of most activities. CO levels decreased to a lesser extent, which is probably due to the fact that steel and coking power industries did not stop. $\mathrm{SO}_{2}$ levels displayed a high reduction in January 2020 but increased and exceeded 2018-19 values in April 2020, which is attributed to the ongoing coal industry and in coal consumption for domestic heating. Ozone levels were higher in 2020 versus $2018-19$, which is explained by less $\mathrm{NO}_{\mathrm{x}}$ pollution because $\mathrm{NO}_{\mathrm{x}}$ reacts with and inhibits ozone precursors. 


\section{Conclusion}

We have studied the spatial and temporal variations of nighttime light and air pollutants during the COVID-19 lockdown in Wuhan. The spatial variations of nighttime light radiance are heterogenous at local scale. The most darkened area during the lockdown was Wuhan downtown due the halt of most companies, services and associated human labour. Yet, an increase of radiance in the five surrounding districts by homestaying people was observed. The daily variation of AQI in Wuhan during the lockdown period showed that almost all data were within the two best air quality categories. Analysis of the February 5 pollution event revealed positive correlations of particulate matter, $\mathrm{SO}_{2}, \mathrm{NO}_{2}$ and $\mathrm{CO}$, and a negative correlation between $\mathrm{O}_{3}$ and $\mathrm{NO}_{2}$. Ozone increased with decreasing $\mathrm{NO}_{2}$ levels, which is explained by chemical titration. Regarding the relationship between air pollutants and meteorological factors during the pollution event, temperature was positively correlated with the concentrations of all pollutants except for $\mathrm{O}_{3}$. Particulate matter, $\mathrm{SO}_{2}, \mathrm{NO}_{2}$ and $\mathrm{CO}$ decreased with relative humidity, suggesting removal by precipitation. The comparison of 2020 mean data during January-April with previous years shows that $\mathrm{PM}_{2.5}, \mathrm{PM}_{10}$ and $\mathrm{NO}_{2}$ declined sharply in 2020; the decrease of $\mathrm{CO}$ was small; $\mathrm{SO}_{2}$ displayed a high reduction in January 2020 but increased and exceeded 2018-19 values in April 2020; due to less $\mathrm{NO}_{\mathrm{x}}$ pollution, ozone levels were higher in 2020 versus $2018-19$.

Supplementary Information The online version contains supplementary material available at https://doi.org/10.1007/s10311-021-01222-x.

Acknowledgements This research was funded by the National Natural Science Foundation of China (Grant No. 42007194); the MOE (Ministry of Education in China) Project of Humanities and Social Sciences (Grant No. 17YJCZH264); the open fund by Jiangsu Key Laboratory of Atmospheric Environment Monitoring and Pollution Control (KHK1907); the Opening Project of Shanghai Key Laboratory of Atmospheric Particle Pollution and Prevention $\left(\mathrm{LAP}^{3}\right)$ (Grant No. FDLAP19003); the Research Fund for Teaching and Research Development of Liberal Arts Teachers in Zhejiang University, and the Basic Science Center Program for Ordered Energy Conversion of the National Natural Science Foundation of China (No. 51888103). The authors are grateful to the China National Environmental Monitoring Centre for making air quality data for 2018-2020 available for Wuhan, China. Our thanks to the Earth Observations Group for providing monthly NPP-VIIRS nighttime light data.

\section{Declarations}

Conflict of interests The authors declare that they have no conflict of interest in this work.

\section{References}

Bao R, Zhang A (2020) Does lockdown reduce air pollution? Evidence from 44 cities in northern China. Sci Total Environ 731:139052. https://doi.org/10.1016/j.scitotenv.2020.139052

Cheng H, Wang Z, Feng J, Chen H, Zhang F, Liu J (2012) Carbonaceous species composition and source apportionment of $\mathrm{PM}_{2.5}$ in urban atmosphere of Wuhan. Ecol Environ Sci 21(9):1574-1579

He G, Pan Y, Tanaka T (2020) The short-term impacts of COVID-19 lockdown on urban air pollution in China. Nat Sustain 3:10051011. https://doi.org/10.1038/s41893-020-0581-y

Huang X, Ding A, Gao J, Zheng B et al (2020) Enhanced secondary pollution offset reduction of primary emissions during COVID19 lockdown in China. Natl Sci Rev. https://doi.org/10.1093/ nsr/nwaa137

Kang Y, Wang Y, Xia Z, Chi J, Jiao L, Wei Z (2018) Identification and classification of Wuhan urban districts based on POI. J Geomat 43(1):81-85 ((In Chinese))

Li J, Tartarini F (2020) Changes in air quality during the COVID-19 lockdown in Singapore and associations with human mobility trends. Aerosol Air Qual Res 20(8):1748-1758. https://doi.org/ 10.4209/aaqr.2020.06.0303

Li L, Li Q, Huang L, Wang Q et al (2020) Air quality changes during the COVID-19 lockdown over the Yangtze River Delta Region: An insight into the impact of human activity pattern changes on air pollution variation. Sci Total Environ 732:139282. https:// doi.org/10.1016/j.scitotenv.2020.139282

Lian X, Huang J, Huang R, Liu C, Wang L, Zhang T (2020) Impact of city lockdown on the air quality of COVID-19-hit of Wuhan city. Sci Total Environ 742:140556. https://doi.org/10.1016/j. scitotenv.2020.140556

Liu Q, Sha D, Liu W, Houser P, Zhang L, Hou R, Lan H, Flynn C, Lu M, Hu T, Yang C (2020a) Spatiotemporal patterns of COVID-19 impact on human activities and environment in China using nighttime light and air quality data. Remote SensBasel 12(10):1576. https://doi.org/10.3390/rs12101576

Liu D, Deng Q, Ren Z, Zhou Z, Song Z, Huang J, Hu R (2020b) Variation trends and principal component analysis of nitrogen oxide emissions from motor vehicles in Wuhan City from 2012 to 2017. Sci Total Environ 704:134987. https://doi.org/10.1016/j. scitotenv.2019.134987

Liu Y, Fang F, Jing Y (2020c) How urban land use influences commuting flows in Wuhan, Central China: A mobile phone signaling data perspective. Sustain Cities Soc 53:101914. https://doi. org/10.1016/j.scs.2019.101914

Ma T, Zhou Y, Zhou C, Haynie S, Pei T, Xu T (2015) Night-time light derived estimation of spatio-temporal characteristics of urbanization dynamics using DMSP/OLS satellite data. Remote Sens Environ 158:453-464. https://doi.org/10.1016/j.rse.2014.11.022

Murphy JG, Day DA, Cleary PA, Wooldridge PJ, Millet DB, Goldstein AH, Cohen RC (2007) The weekend effect within and downwind of Sacramento: Part 1. Observations of ozone, nitrogen oxides, and VOC reactivity. Atmos Chem Phys 7(20):53275339. https://doi.org/10.5194/acp-7-5327-2007

Pan A, Liu L, Wang C, Guo H, Hao H, Wang Q, Huang J, He N, Yu H, Lin X, Wei S, Wu T (2020) Association of public health interventions with the epidemiology of the COVID-19 outbreak in Wuhan. China JAMA 323(19):1915-1923. https://doi.org/10. 1001/jama.2020.6130

Shi X, Brasseur GP (2020) The response in air quality to the reduction of Chinese economic activities during the COVID-19 outbreak. Geophys Res Lett. https://doi.org/10.1029/2020GL088070

Sun Y, Zheng S, Wu Y, Schlink U, Singh RP (2020) Spatiotemporal variations of city-level carbon emissions in China during 
2000-2017 using nighttime light data. Remote Sens-Basel 12(18):2916. https://doi.org/10.3390/rs12182916

Wang C, Horby PW, Hayden FG, Gao GF (2020a) A novel coronavirus outbreak of global health concern. Lancet 395(10223):470-473. https://doi.org/10.1016/S0140-6736(20)30185-9

Wang L, Li M, Yu S, Chen X, Li Z, Zhang Y, Jiang L, Xia Y, Li J, Liu W, Li P, Lichtfouse E, Rosenfeld D, Seinfeld JH (2020b) Unexpected rise of ozone in urban and rural areas, and sulfur dioxide in rural areas during the coronavirus city lockdown in Hangzhou, China: implications for air quality. Environ Chem Lett 18(5):1713-1723. https://doi.org/10.1007/s10311-020-01028-3

Wu, C, Yuan J, Ru L, Chen H, Du B, Zhang L (2020) A measurement of transportation ban inside Wuhan on the COVID-19 epidemic by vehicle detection in remote sensing imagery. ArXiv 2006:16098

Xu H, Zhu J, Wang Z (2019) Exploring the spatial pattern of urban block development based on POI analysis: A case study in Wuhan. China Sustain Basel 11(24):6961. https://doi.org/10.3390/su112 46961

Xu K, Cui K, Young L, Hsieh Y, Wang Y, Zhang J, Wan S (2020) Impact of the COVID-19 event on air quality in central China. Aerosol Air Qual Res 20:915-929. https://doi.org/10.4209/aaqr. 2020.04.0150
Zhang X, Wu J, Peng J, Cao Q (2017) The uncertainty of nighttime light data in estimating carbon dioxide emissions in China: A comparison between DMSP-OLS and NPP-VIIRS. Remote SensBasel 9(8):797. https://doi.org/10.3390/rs9080797

Zheng S, Cao C, Singh RP (2014) Comparison of ground based indices (API and AQI) with satellite based aerosol products. Sci Total Environ 488-489:398-412. https://doi.org/10.1016/j.scitotenv. 2013.12.074

Zheng S, Shan J, Singh RP, Wu Y, Pan J, Wang Y, Lichtfouse E (2020) High spatio-temporal heterogeneity of carbon footprints in the Zhejiang Province, China, from 2005 to 2015: implications for climate change policies. Environ Chem Lett 18(3):931-939. https:// doi.org/10.1007/s10311-020-00977-z

Publisher's Note Springer Nature remains neutral with regard to jurisdictional claims in published maps and institutional affiliations. 